\title{
İnsan Kaynakları Yöneticilerinin İş Becerikliliklerinin İşe Adanmışlıkları Üzerine Etkisi
}

\author{
DOI: $10.26466 /$ opus.513340 \\ *
}

\section{Tahsin Akçakanat ${ }^{*}$ - Hasan Hüseyin Uzunbacak** - Osman Kürşat Acar ${ }^{* * *}$}

*Dr, Öğr. Üyesi, Süleyman Demirel Üniversitesi İktisadi ve İdari Bilimler Fak., Isparta/Türkiye E-Posta: tahsinakcakanat@sdu.edu.tr ORCID:0000-0001-9414-6868

**Dr, Öğr. Üyesi, Süleyman Demirel Üniversitesi İktisadi ve İdari Bilimler Fak., Isparta/Türkiye E-Posta: hasanuzunbacak@sdu.edu.tr ORCID:0000-0002-3297-1659

*** Dr, Öğr. Üyesi, Süleyman Demirel Üniversitesi İktisadi ve İdari Bilimler Fak., Isparta/Türkiye E-Posta: osmanacar@sdu.edu.tr ORCID:0000-0002-1961-645X

\section{$\ddot{O} z$}

Bu çalışmada, Türkçe yazında üzerinde yeni yeni çalışmalar yapılmaya başlanmış olan İş Becerikliliği kavramı ele alınmıştır. Bu kapsamda İş Becerikliliği bağımsız değişsen olmak üzere İşe Adanmışlık üzerine olan etkisi araştırmaya konu edilmiştir. Araştırmanın örneklemi, Akdeniz bölgesinde çeşitli il ve sektörlerde çalışan insan kaynakları yöneticilerinden oluşturulmuştur. Bu kapsamda 230 yöneticiden elde edilen verilerle çalışma gerçekleştirilmiştir. Araştırmada, çalışanların İş Becerekliliğini ölçmek amacıyla Tims ve arkadaşları (2012) tarafindan geliştirilip, Akın ve arkadaşları (2014) tarafindan Türkçeye uyarlanan 21 maddelik ölçek kullanılmıştır. Çalışanların İşe Adanmışlıkları ise Schaufeli ve Bakker (2003) tarafindan geliştirilen ve Özkalp ve Meydan (2015) tarafindan Türkçeye uyarlanan 9 maddelik ölçek ile ölçülmüştür. Çalışmada SPSS 22 ve LISREL 8.80 istatistik paket programları kullanılarak analizler gerçekleştirilmiştir. Betimleyici istatistikler ile korelasyon ve regresyon analizleri bu çalışmada kullanılmıştır. Araştırma sonucunda İş Becerikliliğinin; Yapısal İş Kaynaklarını Artırma, Sosyal İş Kaynaklarını Artırma ve Zorlayı̊ı İş Gerekliliklerini Artırma boyutlarının, İşe Adanmışlık boyutları üzerinde pozitif yönlü ve anlaml etkileri tespit edilmiştir.

Anahtar Kelimeler: İş Becerikliliği, İşe Adanmışlık, İş Gerekleri-Kaynakları Teorisi, İnsan Kaynaklart 


\title{
The Effect of Human Resource Manager's Job Crafting on Work Engagement
}

\begin{abstract}
In this study, the concept of Job Crafting, which has begun to be made in Turkish literature, has been discussed. In this context, the impact of Job Commitment on Work Commitment, which is an independent variable, has been investigated. The sample of the study is composed of human resources managers working in various provinces and sectors in the Mediterranean region in Turkey. In this context, data were obtained from 230 managers. In order to measure the job crafting of employees, a 21-item scale which was developed by Tims et al. (2012) and adapted to Turkish by Akin et al. (2014) was used. Work engagement is measured by the 9-item scale developed by Schaufeli and Bakker (2003) and adapted into Turkish by Özkalp and Meydan (2015). In this study, SPSS 22 and LISREL 8.80 statistical packages were used. Descriptive statistics and correlation and regression analyzes were used in this study. As a result of the research; The positive and significant effects of increasing structural job resources, increasing social job resources and increasing the challenging job demands on work engagement's dimensions have been determined.
\end{abstract}

Keywords: Job Crafting, Work Engagement, Job Demands-Resource Theory, Human Resource 


\section{Giriş}

Son dönemde pozitif psikoloji alanında yapılan çalışmalar, çalışanların psikolojik olarak olumlu olana yönlenmesinin, insan kaynağının gücünün ve performansının geliştirilmesi ve yönetilebilmesine yardımcı olacağını savunmaktadır (Seligman ve Csikszentmihalyi, 2000; Luthans, 2002). Bu bağlamda, çalışma yaşamında, çalışanların yüksek düzeyde performans göstermelerini sağlamak, bu sağlanırken işe ve işyerine karşı olumlu tutum ve davranışlar sergilemelerini teşvik etmek için örgütler ciddi çalışmalar yürütmektedir. Bunun için işlerine kazanç getiren bir faaliyet olmasının ötesinde anlam yüklemeleri, bağlılık, vatandaşlık, mutluluk ve yapılan işten tatmin olmaları gibi konular yöneticilerin ve araştırmacıların oldukça fazla ilgisini çekmektedir.

Son zamanlarda, özellikle yurtdışında insan kaynakları yöneticilerinin ve araştırmacıların ilgisini çeken konulardan birisi de işe adanmışlığın öncülleri ve sonuçları olmaktadır. Çalışanların işlerine fiziksel, duygusal ve bilişsel olarak kendini vererek odaklanmaları olan işe adanmışlığı artıran hususlardan birisi de iş becerikliliğidir. İş becerikliliğini çalışanların bireysel tercihleriyle işleri üzerinde değişiklik ve düzenleme yapması olarak tanımlayan Tims vd. (2010), iş becerikliliğinin işe adanmışlı̆̆ etkilediğini belirtmiştir.

$\mathrm{Bu}$ çalışma ile iş becerikliliğinin işe adanmışlık üzerindeki etkisi, insan kaynakları yöneticileri özelinde test edilmiştir. Yurtdışında yapılan çalışmalarda bu model çokça çalışılmış olmakla birlikte, Türkçe yazında sınırlı çalışmalar bulunmaktadır. Bu anlamda çalışmanın Türkçe yazına katkı sağlayacağı değerlendirilmektedir.

\section{Kavramsal Çerçeve}

Bu başlık altında araştırmada ele alınan İş Becerikliliği ve İşe Adanmışlık kavramları açıklanıp, aralarındaki ilişkiler açıklanmaya çalışılacaktır.

\section{İş Becerikliliği}

Yerli yazına bakıldığında, araştırmanın değişkenlerinden ilki olan "job 
crafting", iş zanaatkârlı̆̆g, iş şekillendirme, iş yapılandırma ve iş becerikliliği olarak dört farklı şekilde ifade edilmiştir. Kavram, Türkçe yazında en çok iş becerikliliği olarak ele alındı̆̆ından, bu araştırmada da iş becerikliliği olarak kullanılmıştır.

İlk kez Wrzesniewski ve Dutton (2001, s.179) tarafından tanımlanan iş becerikliliği, çalışanın bir işi yaparken yürüttüğü faaliyetlerin biçimini veya sayısını değiştirerek görev sınırlarını düzenlemesi, iş yaparken etkileşimde bulunduğu sosyal ortamı değiştirerek ilişkisel sınırlarını şekillendirmesi olarak tanımlanmaktadır. Bir başka tanımda ise, çalışanın işle ilgili koyduğu zihinsel, duygusal, bilişsel, zamansal, ilişkisel ve fiziksel engelleri değiştirmek için proaktif bir davranış sergilemesi olarak ifade edilmiştir (Rastogi ve Chaudhary, 2018, s.657). İş becerikliliği çalışanların, işin özellikleri ile kendi ihtiyaçları, yetenekleri ve tercihleri arasında uyumu geliştirmesi, yapmış oldukları işin monotonluğundan kurtulmak için yeni ve farklı işler yapmasıdır. Ayrıca bu çalışanların, kendilerine daha faydalı olacağını düşündükleri kişilerle ilişki kurarak veya işlerini daha iyi yapabilmek için iş yapma biçimlerini yeniden düzenleyerek işlerinde değişiklik yapabilecekleri belirtilmiştir (Wrzesniewski ve Dutton, 2001: 180; Berg vd., 2008, s.3).

İş becerikliliği, İş Tasarımı Teorisi ve İş Gerekleri-Kaynakları Modeli ile açıklanmaktadır. İş Tasarımı Teorisi, iş ile ilgili bir değişiklik yapılmasının ancak, örgüt veya yönetici tarafından verilecek talimatlarla mümkün olabileceğini ifade etmekte iken, "alternatif iş tasarım tekniğii" olarak ele alınmasıyla birlikte, çalışanların da yaptıkları işleri yeniden düzenleme, şekillendirme, tasarlama imkanına sahip olduğu ifade edilmiştir. Bir başka ifade ile işlerin tasarlanması, yukarıdan aşağıya doğru bir şekilde yapılırken, alternatif iş tasarımı tekniği ile birlikte, iş tasarımında aşağıdan yukarıya doğru bir işleyişinde mümkün olacağı ifade edilmiştir (Yavuz, 2018, s.12). İş Gerekleri-Kaynakları Modeli'ne göre ise, her işin ve çalışma ortamının fiziksel, zihinsel ve duygusal çaba ve yetenekleri içeren bir takım iş gerekleri ve çalışanların işi ile ilgili olumlu çıktılar üretmesine neden olan fiziksel, örgütsel ve sosyal özellikleri içeren iş kaynakları olmak üzere iki karakteristik özelliği bulunmaktadır. Çalışanların işlerinde değişiklik yapmak istemelerinin altında işin gerekleri ve kaynakları arasında dengeye varma çabası yatmaktadır (Tims ve Bakker, 2010, s.3). İşin gerek- 
lerini yerine getirebilmek için çalışanlar çaba göstermek ve bazı maliyetlere katlanmak zorundadır. Bu çabanın ve maliyetin azaltılması için kişisel olarak kendilerini geliştirmek isterler. Teoriye göre, bu amaçla çalışanlar ya iş gereklerinin veya iş kaynaklarının ya da ikisinin birden seviyesini değiştirerek denge ve uyum yakalamaya çalışırlar (Tims vd., 2013, s.231).

İş becerikliliği ile ilgili yazında, kavramı oluşturan boyutlar ile ilgili farklı yaklaşımlar söz konusudur. Bu araştırmada, İş Gerekleri-Kaynakları Modeli kapsamında Tims ve arkadaşları (2012) tarafından yapılan sınıflandırma benimsenmiştir. Tims ve arkadaşları, iş becerikliliğini dört boyutlu bir yapıda ele almışlardır (Mamak, 2018, s.16-18). Bu boyutlardan ilki olan Yapısal İş Kaynaklarını Artırma (YİKA), kendisinden istenenleri yerine getirebilmek için kişisel gelişim, öğrenme ve gelişme, beceri çeşitliliği gibi yollarla iş kaynaklarını koruma ve artırma anlamına gelmektedir. İkinci boyut olan Engelleyici İş Kaynaklarını Azaltma (EİGA) ise, çatışma, tükenmişlik gibi olumsuz iş çıktılarından korunmak amacıyla, iş taleplerini azaltma yoluyla çalışanın kendisini korumaya çalışması olarak ifade edilmektedir. Sosyal İş Kaynaklarını Artırma (SİKA) boyutu, çalışanların geri bildirim, destek alma gibi yollarla iş arkadaşları ve iletişim halinde olduğu çevre ile sürdürdüğü ilişkisini geliştirerek iş kaynaklarını artırmaya çalışmasıdır. Dördüncü boyut olan Zorlayıcı İş Gereklerini Artırma (ZİGA) ise, gönüllü olarak iş tanımları dışında görevler almak, yeni bilgiler ve becerilere merak duyarak yeteneklerini geliştirmek, sahip olduğu sorumlulukları artırmak istemesidir.

İş becerikliliği ile ilgili araştırmalara bakıldığında, iş becerikliliğinin öncülleri ve sonuçları olarak algılanan örgütsel destek, yaratıcı özyeterlilik, özerklik, işkoliklik, işe adanmışlık, proaktif kişilik, akış deneyimi, iyi oluş, iş tatmini, performans, tükenmişlik, yaratıcllık gibi pek çok örgütsel davranış değişkeni ortaya konulmuştur (Kim vd., 2018); Zeijen vd., 2018; Tims vd., 2013; Bakker, 2012; Petrou vd., 2015; Demerouti vd., 2015).

\section{İşe Adanmışlık}

İş becerikliliğinde olduğu gibi, "work engagement" kavramı da Türkçe'ye uyarlanırken farklı şekillerde ifade edilmiştir. İşe angaje olma, cezbolma, işe tutkunluk, işle bütünleşme, işe gönülden adanma, işe bağlılık ve işe adanmışlık gibi ifadeler kullanılmaktadır (Ardıç ve Polatçı, 2009, s.36). Bu 
çalışmada, daha yaygın olarak kullanılması sebebiyle işe adanmışlık tercih edilmiştir.

İşe adanmışlık en genel anlamda, çalışanların fiziksel, duygusal ve bilişsel olarak kendini işe vererek işlerine odaklanmaları olarak tanımlanmaktadır (Kahn, 1990, s.694). Bir başka tanımda ise işe adanmışlık, çalışanların işini özümseyerek, yaptığ1 işe gömülerek ve kendini adayarak işini yapması ve bunun sonucunda olumlu ve tatmin edici zihinsel durum yaşaması olarak ifade edilmektedir (Schaufeli ve Bakker, 2006, s.702). Tükenmişlik ve işten ayrılma niyeti gibi işle ilgili olumsuz duyguların tersi olduğu (Özkalp ve Meydan, 2015, s.5) değerlendirilen işe adanmışlık, çalışanların kendilerinden ne beklendiğini bilerek ve çevrelerindeki bireylerle iyi ilişkiler kurarak, yaptığı işe bağlanması, arzu ve ilgi duyması, tutkuyla, hevesle, gayretle ve enerjiyle yaklaşması anlamına gelen tutumsal ve davranışsal bir durumdur (Macey ve Schneider, 2008, s.4). İşe adanmış çalışanlar, kendilerine inanan, kendileri ile ilgili olumlu geri bildirimlerde bulunan, bireysel amaçlarını örgütün amaçlarıyla uyumlu hale getiren, ne kadar yorgun ve tükenmiş hissetse de yaptığı işten memnun olan, işkolik olmayan ama işlerine bağımlı bireyler olarak nitelendirilmiştir (Bakker ve Demerouti, 2008, s.210). İşe etkin bir şekilde dahil olma, işi yaşamın merkezine alma, işi ile özsaygısı arasında bağlantı kurma, kendini iş performansı ile ifade etme, işe adanmış çalışanların özellikleri arasında sayılmaktadır (Balay, 2014, s.52). İşe adanmışlık ile ilgili çalışmalar, iş-aile çatışması, tükenmişlik, aşırı iş yükü, sosyal destek, özerklik, özyeterlilik, geri bildirim, örgüt iklimi, örgütsel bağlılık, performans, işten ayrılma niyeti, iş tatmini, liderlik, kişilik gibi değişkenleri ilişkili kavramlar arasında saymaktadir (Halbesleben, 2010, s.111; Christian, 2011, s.96).

İşe adanmışlık kavramı, iş becerikliliğinde olduğu gibi İş GerekleriKaynakları Modeli'ne dayandırılmaktadır. Sezgisel (sonucun doğruluğunun kanıtlanabilir olup olmadığını önemsemeyen, genelde iyiye yakın çözüm yolları elde eden) bir model olarak ele alınan bu yaklaşıma göre çalışanların, işlerini yaparken zorlanmalarına neden olan ve işin özellikleri olarak belirtilen iş gereklerini yerine getirmek için çabalamaları, performanslarını sürekli olarak yüksek tutmak istemeleri, olumsuz bir takım fizyolojik ve psikolojik çıktılara sebep olabilmektedir. Maaş, iş güvenliği, kariyer fırsatları, katılım, özerklik, geribildirim gibi çalışma koşullarını temsil eden iş kaynakları ise, çalışanların amaçlarına ulaşmasını kolaylaştıran, 
iş gereklerini azaltan ve bireysel olarak çalışanların gelişimlerini destekleyen faktörler olarak ifade edilmektedir (Bakker vd., 2004; Demerouti vd. 2001). İş gerekleri ve kaynakları arasında dengenin sağlanması, çalışanların hedeflerine ulaşma yönündeki çabasını tetikleyerek, işlerine karşı motivasyonunu yükseltip, işe adanmışlıklarının artmasına ve dolayısıyla iyi performans sergilemelerine neden olabilmektedir (Bakker ve Demerouti, 2007, s.314).

Schaufeli (2002, s.74-75), işe adanmışlığı, dinçlik, kendini adama ve özümseme olmak üzere üç boyutlu bir yapıda ele almıştır. Dinçlik, çalışanın işini yaparken zorluklarla karşılaşması durumunda bile, enerjik ve psikolojik olarak dayanıklı bir biçimde işi için çaba göstermeye sabırla ve istekle devam etmesi anlamına gelmektedir. Kendini Adama, çalışanın yaptığı işe anlam ve değer vererek, gurur, coşku ve meydan okuma duygularıyla çalışması halidir. Özümseme ise, çalışanın işine tamamen odaklanması, kendini işine derinlemesine vermesi halidir. Öyle ki, bu durumdaki çalışan, zamanın nasıl geçtiğini anlamaz ve işi bırakmakta zorlanır. Bir başka ifadeyle özümseme, pozitif psikolojideki akış deneyimini yaşaması halidir.

\section{Değişkenler Arası İlişkiler ve Hipotezlerin Oluşturulması}

İş becerikliliği ile işe adanmışlık arasındaki ilişki, önceki bölümlerde de belirtildiği gibi İş Gerekleri-Kaynakları Teorisi bağlamında ele alınmaktadır. İş becerikliliği çalışanların proaktif davranışlar sergilemesiyle ortaya çıkan bir durumdur. Bu durum, çalışanların işleriyle ilgili duygularını pozitif etkileyerek, iş kaynaklarını geliştirir ve onların işe adanmışlık duygusunu etkiler (Bakker vd., 2011; Petrou vd., 2012; Tims vd., 2012, Uysal vd., 2018).

İş becerikliliği davranışlarına; geri bildirim ve koçluk (sosyal iş kaynaklarını arttırma), özerkliği artırma ve işyerinde kendini geliştirme (yapısal kaynakları arttırma), yeni projeler başlatma (zorlu iş taleplerini artırma) ve iş yükünü azaltma (engelleyici iş taleplerinin azaltılması) gibi örnekler verilebilir. İş becerikliliği davranışları ile çalışanlar tarafından, proaktif olarak işlerde ve işin sınırlarında, iş gerekleri ve kaynakları ile ilgili değişiklik ve düzenlemeler yapılabilir (Tims ve Bakker, 2010). Bu değişiklik ve düzenlemeler çalışanların, bireysel ihtiyaçları, yetenekleri ve 
işe karşı tutkuları ile iş arasında uyumu ortaya çıkararak, işe adanmışlıklarını artırabilir (Bakker vd., 2013; Van Wingerden vd., 2015: 54). Bir başka ifadeyle, iş becerikliliği davranışları, çalışanların dinamik olarak işleriyle daha fazla meşgul olmalarını sağlamaktadır. Bu dinamizm ve çaba, çalışanların işe adanmışlık duygusuyla hareket etmesine neden olabilmektedir (Van Wingerden ve Poell, 2017: 3). Buradan hareketle, araştırmada şu hipotez oluşturulmuştur:

$H_{i j}$ : $\dot{I}_{s ̧}$ becerikliliğinin (i) alt boyutu, işe adanmışlı̆̆ın (j) alt boyutunu anlamlı bir şekilde etkiler.
(i): $1,2,3,4$
1: YİKA; 2: EİGA; 3: SİKA; 4: ZİGA
(j): $a, b, c$
a: Dinçlik; b: Kendini Adama; c: Özümseme

\section{Araştırmanın Metodolojisi}

Araştırmanın amacı, tasarlanan araştırma modeli, örneklem kitlesi ve veri toplama araçları hakkında ayrıntılı bilgilere aşağıda yer verilmiştir.

\section{Araştırmanın Amacı ve Modeli}

Bu çalışmada, iş becerikliliğinin işe adanmışlık üzerindeki etkisi araştırılmıştır. Bu amaçla iş becerikliliğinin alt boyutlarını oluşturan "Yapısal İş Kaynaklarını Artırma (YİKA)”, “Engelleyici İş Gerekliliklerini Azaltma (EİGA)”, "Sosyal İş Kaynaklarını Artırma (SİKA)" ve “Zorlayıcı İş Gerekliliklerini Artırma (ZİGA)" nın, işe adanmışlığın alt boyutlarını oluşturan "Dinçlik", "Kendini Adama" ve "Özümseme" üzerine olan etkisi incelenmiştir. Bu kapsamda oluşturulan araştırma modeli şekil 1'de verilmiştir.

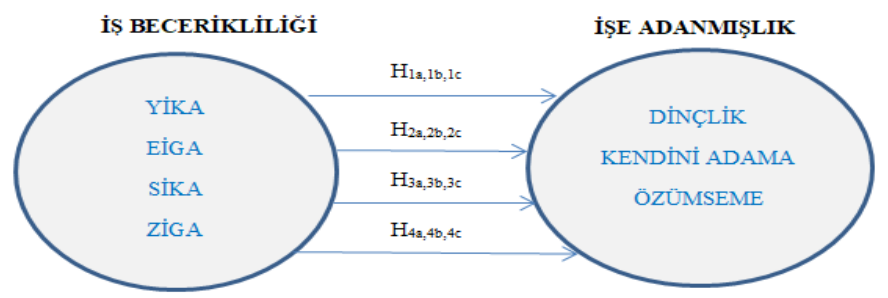

Şekil 1. Araştırma Modeli 


\section{Araştırmanın Örneklemi}

Bu çalışmanın örneklemi çeşitli sektörlerde görev yapan insan kaynakları yöneticilerinden oluşmaktadır. İnsan kaynakları yöneticilerinin meslek icabı olarak, iş becerikliliğini göstermek zorunda oldukları düşünülerek örneklem belirlenmiştir. Bu kapsamda, Süleyman Demirel Üniversitesi İktisadi ve İdari Bilimler Fakültesi İnsan Kaynakları Yönetimi bölümünün, Akdeniz Bölgesinde çeşitli kuruluşlarda görev yapan insan kaynakları yöneticilerine yönelik gerçekleştirdiği geniş kapsamlı bir toplantı öncesinde, tamamen gönüllülük esasına dayalı olarak anket formları katılımcılara dağıtılmış ve sonrasında toplanmıştır. Kolayda örnekleme yöntemi kullanılarak yapılan bu çalışmada, 230 adet geçerli anket formu elde edilmiştir. Literatürde örneklem büyüklüğünün en az 150 kişiden oluşması (Anderson ve Gerbing, 1988) gerektiği ifade edildiği için çalışmada ulaşılan örneklem sayısının, evreni temsil becerisine sahip olduğu söylenebilir.

\section{Veri Toplama Araçları}

Bu çalışmada, veri toplama tekniği olarak anket yöntemi kullanılmıştır. Çalışmada iki ölçek kullanılmış olup aşağıda bu ölçekler hakkında ayrıntılı bilgiler aşağıda verilmiştir. Çalışma bu iki ölçeğin haricinde 6 sorudan oluşan demografik bilgi formu da kullanılmıştır.

Işs Becerikliliği Ölçeği: Tims ve arkadaşları (2012) tarafından geliştirilen 21 madde ve 4 alt boyuttan (Yapısal iş kaynaklarını artırma, Engelleyici iş gerekliliklerini azaltma, Sosyal iş kaynaklarını artırma, Zorlayıcı iş gerekliliklerini artırma) oluşan ölçeğin Türkçe uyarlaması Akın ve arkadaşları (2014) tarafından yapılmıştır. 5'li likert şeklinde tasarlanan (1= Kesinlikle Katılmıorum, 5= Kesinlikle Katılıyorum) ölçekte ters puanlanmış madde bulunmamaktadır. Akın ve arkadaşları (2014), iç tutarlık güvenirlik katsayılarını; yapısal iş kaynaklarını arttırma alt boyutu için .72, engelleyici iş gerekliliklerini azaltma alt boyutu için .75, sosyal iş kaynaklarını arttırma alt boyutu için .90 ve zorlayıcı iş gerekliliklerini arttırma alt boyutu için .76 olarak bulmuştur. Ölçekte yer alan maddelere örnek olarak, "İşimi 
çok uzun süre boyunca yoğunlaşmak zorunda kalmayacă̆ım şekilde organize ederim" ile "İşimin farkl yönlerinin arasındaki ilişkileri inceleyerek; işimi daha zorlayıcı hale getirmeye çalışırım" gösterilebilir.

Işe Adanmışlık: Schaufeli ve Bakker (2003) tarafından geliştirilen ölçek 3 boyut (Dinçlik, Kendini Adama ve Özümseme) ve 9 maddeden oluşmaktadır. 7'li likert şeklinde tasarlanan (1= Asla, 7= Sıklıkla) ölçekte ters puanlanmış madde bulunmamaktadır. Ölçeğin Türkçe'ye uyarlama çalışması Özkalp ve Meydan (2015) tarafından gerçekleştirilmiştir. Özkalp ve Meydan (2015), iç tutarlık güvenirlik katsayılarını; Dinçlik alt boyutu için .80, Kendini Adama alt boyutu için .79 ve Özümseme alt boyutu için .64 olarak bulmuştur. Ölçekte yer alan maddelere örnek olarak, "İşimi yaparken kendimi çok enerjik hissederim" ile "Çalışırken kendimden geçiyorum" gösterilebilir.

\section{Veri Toplama Araçlarının Geçerlilik ve Güvenilirlikleri}

Araştırmada kullanılan ölçeklerin yapısal açıdan geçerli olup olmadıklarını ortaya koymak için Lisrel 8.80 programı kullanılarak doğrulayıcı faktör analizi (DFA) yapılmıştır. DFA sonuçları Tablo 1'de verilmiştir.

Tablo 1. Ölçeklerin Uyum İyiliği Değerleri

\begin{tabular}{lcccccccc}
\hline Model & $\chi^{2} / \mathbf{d f}$ & CFI & NFI & NNFI & GFI & AGFI & SRMR & RMSEA \\
\hline İş Becerikliliği & 1,79 & .92 & .95 & .96 & .91 & .87 & .067 & .059 \\
İşe Adanmişlık & 2,24 & .99 & .98 & .97 & .96 & .91 & .035 & .074 \\
\hline Kabul Edilebilir Uyum* & $\leq 5$ & $>0.90$ & $>0.90$ & $>0.90$ & $>0.85$ & $>0.80$ & $<0.08$ & $<0.08$ \\
İyi Uyum* & $\leq 3$ & $>0.97$ & $>0.95$ & $>0.97$ & $>0.90$ & $>0.85$ & $<0.05$ & $<0.05$ \\
\hline *Joreskog ve Sorbom, (1993); Kline, (1998); Anderson ve Gerbing, (1984). & & &
\end{tabular}

Tablo 1 değerlendirildiğinde araştırmada kullanılan her iki ölçeğin de uyum iyiliği değerlerinin kabul edilebilir sınırlar içinde olduğu tespit edilmiştir. İş becerikliliği ölçeğinde, uyum iyiliği değerlerini yakalayabilmek için düşük faktör yüküne sahip YİKA ve ZİGA boyutlarından birer, EİGA boyutundan ise iki madde analiz dışında bırakılmıştır. Sonuç itibariyle, iş becerikliliği ölçeğinin 4 boyutlu, işe adanmışlık ölçeğinin ise 3 boyutlu yapısı doğrulanmıştır. 
Ölçeklerin güvenilirlikleri iç tutarlılık katsayıları ile hesaplanmıştır. Tablo 2'de güvenilirlik analizi sonuçları verilmiştir.

Tablo 2. Ölçeklerin Güvenilirlikleri

\begin{tabular}{lcccc}
\hline Değişken & Madde Sayısı & Çarpıklık & Basıklık & $\alpha$ \\
\hline YíKA & 4 & -.724 & .065 & .74 \\
EIGA & 4 & -.443 & -.185 & .75 \\
SİKA & 5 & -.644 & .271 & .71 \\
ZíGA & 4 & -.547 & .094 & .72 \\
DİNÇLIK & 3 & -.083 & -.683 & .82 \\
KENDİNİ ADAMA & 3 & -.218 & -.678 & .81 \\
ÖZÜMSEME & 3 & -.425 & .131 & .65 \\
\hline
\end{tabular}

Tablo 2 incelendiğinde, Özümseme boyutu hariç olmak üzere diğer tüm değişkenlerin iç tutarlılık katsayılarının kabul edilebilir limit olan .70'in (Nunnally, 1978) üzerinde olduğu görülmektedir. Yazında, .60'ın üzerindeki katsayıların da oldukça güvenilir olduğuna ilişkin görüşler bulunmaktadır (Özdamar, 1999). Bu doğrultuda araştırmada kullanılan veri toplama araçlarının geçerli ve güvenilir oldukları sonucuna varılmıştır. Tablo 2'de ayrıca değişkenlere ait çarpıklık ve basıklık katsayıları da görülmektedir. Bu katsayılar incelendiğinde, verilerin normal dağılım gösterdikleri tespit edilmiştir. Morgan ve arkadaşlarına (2004: 49) göre, çarpıklık ve basıklık katsayılarının \pm 1 aralığında değerler alması durumunda verilerin normal dağılım gösterdiği söylenebilir.

\section{Bulgular}

Araştırmaya katılan insan kaynakları yöneticilerinin demografik özelliklerine ilişkin bilgiler Tablo 3'de sunulmuştur.

Tablo 3'ten görülebileceği gibi katılımcıların \%64.3'ü gibi büyük bir çoğunluğu erkeklerden oluşmaktadır. Yine \%60.8 ortalama ile evli çal1şanlar daha fazla sayıdadır. Ĕ̆itim seviyesi açısından katılımcılar incelendiğinde, lisans eğitimine sahip olan çalışanların \%55.7'lik oranla yarıdan fazla bir paya sahip oldukları tespit edilmiştir. İnsan kaynakları yöneticilerinden, lisansüstü eğitim alanların fazlalığı da yine Tablo 3 aracılığıyla anlaşılmaktadır. 
Tablo 3. Katılımcıların Demografik Özelliklerine İlişkin Bilgiler

\begin{tabular}{llcc}
\hline Demografik Özellikler & & Sayı & Yüzde \\
\hline \multirow{2}{*}{ Cinsiyet } & Kadın & 82 & 35.7 \\
& Erkek & 148 & 64.3 \\
\hline \multirow{2}{*}{ Medeni Durum } & Evli & 140 & 60.8 \\
& Bekâr & 90 & 39.2 \\
\hline \multirow{3}{*}{ Eğitim Düzeyi } & Lise & 34 & 14.8 \\
& Önlisans & 39 & 17.0 \\
& Lisans & 128 & 55.7 \\
& Lisansüstü & 29 & 12.5 \\
\hline TOPLAM & & $\mathbf{2 3 0}$ & $\mathbf{1 0 0 . 0}$ \\
\hline
\end{tabular}

Katılımcıların yaş dağılımları 19 ile 66 yaş arasında değişmekte olup ortalama yaş 37.1 (SS=9.50) olarak tespit edilmiştir. Katılımcıların kıdem ortalamaları ise 13.6 (SS=9.57) yıl olarak bulunmuştur.

Araştırmada kullanılan iş becerikliliği ve işe adanmışlık ölçeklerine ilişkin betimleyici istatistikler ile değişkenler arası ilişkiler Tablo $4^{\prime}$ te gösterilmektedir.

Tablo 4. Betimsel İstatistikler ve Değişkenler Arası İlişkiler

\begin{tabular}{|c|c|c|c|c|c|c|c|c|c|}
\hline $\begin{array}{l}\text { Değişkenler } \\
(\mathrm{N}=230)\end{array}$ & Ort. & S.S. & 1 & 2 & 3 & 4 & 5 & 6 & 7 \\
\hline 1. YİKA & 4.50 & .464 & $(.74)$ & & & & & & \\
\hline 2. EİGA & 3.79 & .706 & .120 & $(.75)$ & & & & & \\
\hline 3. SİKA & 3.73 & .771 & .105 & $.155^{*}$ & $(.71)$ & & & & \\
\hline 4. ZİGA & 3.73 & .755 & $.212^{* *}$ & .007 & $.280^{* *}$ & $(.72)$ & & & \\
\hline 5. DİNÇLIKK & 4.98 & 1.183 & $.266^{* *}$ & $\begin{array}{c}- \\
.020\end{array}$ & $.225^{* *}$ & $.267^{* *}$ & $(.82)$ & & \\
\hline $\begin{array}{l}\text { 6. KENDINİ } \\
\text { ADAMA }\end{array}$ & 5.07 & 1.257 & $.281^{* *}$ & $\begin{array}{c}- \\
.029\end{array}$ & $.218^{* *}$ & $.314^{* *}$ & $.780^{* *}$ & $(.81)$ & \\
\hline 7. ÖZÜMSEME & 4.72 & 1.335 & .086 & .068 & $.142^{*}$ & $.274^{* *}$ & $.371^{* * *}$ & $.456^{* *}$ & $(.65)$ \\
\hline
\end{tabular}

$\left(p<.05\right.$ için *, $p<.01$ için $\left.{ }^{* *}\right)$. Parantez içerisindeki değerler boyutların güvenilirlik katsayılarını göstermektedir.

Tablo 4'te yer alan aritmetik ortalama değerlerine incelendiğinde, 5 üzerinden yapılan değerlendirmelere göre insan kaynakları yöneticilerinin iş becerikliliği seviyelerinin yüksek sayılabilecek düzeyde olduğu görülmektedir. Buna göre insan kaynakları yöneticilerinin en yüksek aritmetik ortalama elde ettikleri boyut 4.50 (SS= .464) ile YIKKA boyutu olmuştur. Bunu takiben sırasiyla EİGA, SIKA ve ZİGA boyutları gelmektedir. Bu 3 
boyutun da ortalamaları birbirine çok yakın seviyede gerçekleşmiştir. İnsan kaynakları yöneticilerinin işe adanmışlık düzeyleri incelendiğinde de yine göreceli olarak yüksek kabul edebileceğimiz ortalamalar karşımıza çıkmaktadır. İşe adanmışlık ölçeğinde en yüksek ortalama 5.07 (SS=1.257) ile kendini adama boyutunda tespit edilmiştir. Onu dinçlik ve özümseme boyutları takip etmektedir.

Tablo 4'te yer alan korelasyon analizi sonuçları incelendiğinde, iş becerikliliğinin boyutlarından YİKA, SİKA ve ZİGA ile işe adanmışlığın 3 boyutu arasında pozitif yönlü, düşük ve orta kuvvet seviyesinde, anlamlı ilişkiler tespit edilmiştir. İş becerikliliğinin sadece EIGA boyutu, işe adanmışlık boyutları ile anlamlı ilişki göstermemektedir. İlişkiler incelendiğinde, en yüksek ilişki ZİGA ile kendini adama boyutu arasında gerçekleşmiştir ( $\mathrm{r}=.314 ; \mathrm{p}<.01)$. Bunu sırasıyla YİKA ile kendini adama $(\mathrm{r}=.281$; $\mathrm{p}<.01)$, ZİGA ile özümseme $(\mathrm{r}=.274 ; \mathrm{p}<.01)$ boyutları takip etmektedir.

Hipotez testlerini gerçekleştirmek yani iş becerikliliğinin işe adanmışlık üzerine etkisini ortaya koyabilmek amacıyla, boyutlar bazında hiyerarşik regresyon analizi gerçekleştirilmiştir. Analizin ilk basamağında, demografik değişkenlerin etkileri kontrol altına alınmak maksadıyla analize dahil edilmiştir. Bu sayede iş becerikliliği boyutlarının, işe adanmışlık boyutları üzerine olan etkisi daha iyi bir şekilde ortaya koyulacaktır. Analiz başlamadan regresyon analizinin varsayımları teste tabi tutulmuştur. Buna göre varsayımlardan birisi olan otokorelasyonun varlığı Durbin Watson katsayısı ile sınanmıştır. Bu katsayının 1.5 ile 2.5 (Kalaycı, 2005, s.264) arası bir değer alması otokorelasyonun olmadığını göstermektedir. Bu çalışmada Durbin Watson katsayıları 1.641 ile 1.833 arasında değerler almıştır. Bu kapsamda regresyon analizinin ilk şartının sağlandığı söylenebilir. Bir diğer varsayım, bağımsız değişkenler arasında çoklu bağlantının olmamasıdır. Bu kapsamda öncelikle bağımsız değişkenler olan iş becerikliliğinin boyutları arasındaki ilişkiler incelenmiş ve .280'ün üzerinde bir ilişki tespit edilememiştir. Bağımsız değişkenler arasında yüksek bir ilişki tespit edilmemesine rağmen varsayımı tam anlamıyla sınamak için Tolerans ve VIF (varyans artış faktörü) değerleri de incelenmiştir. Regresyon analizinde, Tolerans değerinin .20'den büyük; VIF değerinin ise 10 'dan küçük olması arzu edilir (Field, 2009). Oluşturulan 3 regresyon modelinde elde edilen sonuçlar incelendiğinde, VIF değerlerinin 1.058 ile 1.132 arasında, Tolerans değerlerinin ise .884 ile .945 aralığında olduğu 
tespit edilmiştir. Bu doğrultuda bağımsız değişkenler arasında bir çoklu bağlantıdan söz etmek mümkün değildir.

Tablo 5'te görülebileceği gibi oluşturulan 3 model ile iş becerikliliğinin 4 boyutunun aynı anda, sırasıyla dinçlik, kendini adama ve özümseme boyutları üzerine olan etkisi ortaya koyulmaya çalışılmıştır. Bu kapsamda, ilk modelde görüleceği üzere, demografik değişkenler kontrol altında iken YİKA $(\beta=.270, \mathrm{p}<.001)$, SİKA $(\beta=.173, \mathrm{p}<.001)$ ve ZİGA'nın $(\beta=.132, p<.05)$ dinçliği pozitif yönlü ve anlamlı bir şekilde yordadı̆̆ı tespit edilmiştir. EIGA ( $\beta=-.059, \mathrm{p}>.05)$ boyutunun ise dinçlik üzerinde anlamlı bir etkisi bulunmamaktadır. Bu 4 değişken dinçliği \%14.9 seviyesinde açıklamaktadır. Elde edilen sonuçlar uyarınca araştırmanın $\mathrm{H}_{1 a}, \mathrm{H}_{3 a}$ ve $\mathrm{H}_{4}$ hipotezleri kabul edilmiştir.

Tablo 5. İşe Adanmışlık Boyutları İçin Hiyerarşik Regresyon Analizi Sonuçları

\begin{tabular}{|c|c|c|c|c|c|c|c|c|c|}
\hline \multirow{3}{*}{$\begin{array}{l}\mathrm{N}=230 \\
\text { Değiş- } \\
\text { kenler }\end{array}$} & \multirow{2}{*}{\multicolumn{3}{|c|}{$\begin{array}{c}\text { DİNÇLİK } \\
\text { Model } 1\end{array}$}} & \multicolumn{3}{|c|}{ KENDİNI ADAMA } & \multicolumn{3}{|c|}{ ÖZÜMSEME } \\
\hline & & & & & Model & & & Model & \\
\hline & B & S.H. & $\beta$ & B & S.H. & $\beta$ & B & S.H. & $\beta$ \\
\hline $\begin{array}{l}\text { Cinsi- } \\
\text { yet }\end{array}$ & -.037 & .154 & -.015 & -.022 & .161 & -.008 & -.187 & .182 & -.066 \\
\hline Yaş & -.021 & .018 & -.160 & -.014 & .018 & -.104 & $-.061^{* *}$ & .021 & $-.412^{* *}$ \\
\hline $\begin{array}{l}\text { Medeni } \\
\text { Hal }\end{array}$ & -.168 & .167 & -.070 & -.271 & .174 & -.105 & -.262 & .197 & -.095 \\
\hline Kıdem & $.046^{* * *}$ & .016 & $.369^{* * *}$ & $.041^{*}$ & .017 & $.309^{*}$ & $.070^{* * *}$ & .019 & $.496^{* * *}$ \\
\hline YİKA & $.676^{* * *}$ & .163 & $.270^{* * *}$ & $.723^{* * *}$ & .170 & $.271^{* * *}$ & .086 & .192 & .030 \\
\hline EİGA & -.097 & .104 & -.059 & -.110 & .109 & -.063 & .116 & .123 & .061 \\
\hline SİKA & $.266^{* * *}$ & .099 & $.173^{* * *}$ & $.254^{*}$ & .103 & $.155^{*}$ & .126 & .117 & .072 \\
\hline ZİGA & $.207^{*}$ & .102 & $.132^{*}$ & $.311^{* *}$ & .107 & $.186^{* *}$ & $.427^{* * *}$ & .121 & $.238^{* * *}$ \\
\hline$F$ & & $7.009^{* * *}$ & & & $8.242^{* * * *}$ & & & $4.772^{* * *}$ & \\
\hline $\mathbf{R}^{2}$ & & .210 & & & .238 & & & .153 & \\
\hline$\Delta \mathrm{F}$ & & $9.919^{* * *}$ & & & $11.697^{* * *}$ & & & $4.976^{* * *}$ & \\
\hline$\Delta \mathrm{R}^{2}$ & & .149 & & & .169 & & & .080 & \\
\hline
\end{tabular}

Tablo 5'te ikinci model incelendiğinde, yine demografik değişkenler kontrol altında iken, YİKA $(\beta=.271, \mathrm{p}<.001)$, SIKA $(\beta=.155, \mathrm{p}<.05)$ ve ZIGA'nın $(\beta=.186, p<.01)$ kendini adama boyutunu pozitif yönlü ve anlamlı bir şekilde yordadığı tespit edilmiştir. EIGA $(\beta=-.063, \mathrm{p}>.05)$ boyutunun ise kendini adama boyutu üzerinde anlamlı bir etkisi bulunmamak- 
tadır. Bu 4 değişken kendini adama boyutunu \%16.9 seviyesinde açıklamaktadır. Elde edilen sonuçlar uyarınca araştırmanın $\mathrm{H}_{1 \mathrm{~b}}, \mathrm{H}_{3 \mathrm{~b}}$ ve $\mathrm{H}_{4 \mathrm{~b}}$ hipotezleri kabul edilmiştir.

Tablo 5'te son olarak üçüncü model ele alındığında, demografik değişkenler kontrol altında iken, YİKA $(\beta=.030, \mathrm{p}>.05)$, EİGA $(\beta=.061, \mathrm{p}>.05)$ ve SÍKA'nın ( $\beta=.072, p>$.05) özümsemeyi anlamlı bir şekilde yordamadığ1 tespit edilmiştir. ZİGA $(\beta=.238, p<.001)$ boyutunun ise özümseme üzerinde anlamlı bir etkisi bulunmaktadır. Bu 4 değişken özümsemeyi \%8 seviyesinde açıklamaktadır. Elde edilen sonuçlar uyarınca araştırmanın $\mathrm{H}_{4 \mathrm{c}}$ hipotezi kabul edilmiştir.

\section{Sonuç ve Tartışma}

$\mathrm{Bu}$ araştırmanın önemli amaçlarından birisi, iş becerikliliği değişkeni ile henüz Türkçe yazında yeterli düzeyde araştırmanın yapılmamış olmasından kaynaklanan eksikliğin giderilmesidir. Bir diğer amaç ise insan kaynakları politikalarının ve planlamalarının önemli aktörleri olan insan kaynakları yöneticilerinin, iş becerikliliği ve işe adanmışlık anlamında kendilerini ne düzeyde gördügünü belirlemektir. Nitekim, bir organizasyonda yöneticilerin işe karşı olumlu tutum ve davranışlarının diğer tüm çalışanları da olumlu etkilediği artık birçok araştırmanın sonuçları ile kanıtlanmış bir gerçek olarak karşımızda durmaktadır (Zhu vd., 2005; DeGroot vd., 2005; Tarım, 2018; Ürü Sanı vd., 2013).

Bu bağlamda araştırmanın sonuçlarına bakıldığında, iş becerikliliğinin YİKA, SİKA ve ZİGA boyutları ile işe adanmışlığın tüm boyutları arasında anlamlı ilişki tespit edilmiştir. Bu ilişkinin etki düzeyini ve yönünü belirlemek için yapılan regresyon analizi neticesinde ise iş becerikliliğinin boyutlarının (EIGGA dışında), işe adanmışlığın boyutlarından dinçlik ve kendini adama boyutlarını pozitif yönlü ve anlamlı olarak etkilediği belirlenmiştir. Ancak, özümseme boyutuna anlamlı bir etki yapmadığı anlaşılmıştir.

Bu sonuçlar incelendiğinde, Bakker vd. (2012)'nin çeşitli organizasyonlarda çalışan 195 kişi ve Tims vd. (2013)'nin iş sağlığı alanında hizmet veren büyük bir şirkette çalışan 525 kişiyle yaptıkları araştırmaların sonuçlarıyla kısmen uyum sağladığı görülmüştür. Bahsi geçen çalışmalarda, iş becerikliliğinin tüm boyutlarının işe adanmışlı̆ıın tüm boyutlarını anlamlı 
ve pozitif etkilediği belirlenmişken, bu çalışmada EİGA boyutunun işe adanmışlık boyutları üzerinde anlamlı etkisinin olmaması, diğer boyutların (YİKA, SİKA, ZİGA) ise işe adanmışlı̆̆ın özümseme boyutunu etkilemiyor olması, en önemli farklılık olarak tespit edilmiştir. 95 kişi ile yapılan diğer bir araştırmada, iş becerikliliği üç faktörlü bir yapıda ele alınmış olsa da, kaynakların azaltılması ile ilgili iş becerikliliği boyutunun işe adanmışlık ile ilişkisinin olmadığı belirlenmiştir (Petrou vd., 2012). Yine benzer şekilde, Lu vd. (2014) tarafından Çin'deki ileri teknoloji işletmeleri çalışanları üzerinde yapılan araştırmada da iş becerikliliği fiziksel, ilişkisel ve psikolojik boyutlarıyla ele alanmış ve işe adanmışlık ile her üç boyut arasında ilişki bulunmuştur. Demerouti vd. (2015)'nin iş becerikliliği ile ekstra rol davranışları arasındaki ilişkide işe adanmışlık ve akış deneyiminin rolünü test etmek için 295 çalışan üzerinde yaptıkları çalışmada, iş becerikliliği ile işe adanmışlık arasında orta düzeyde ilişki bulunmuştur. Bu sonuçlar, araştırmanın sonuçlarıyla da kısmen örtüşmektedir. Bu değişkenler arasındaki ilişkiyi test etmek amacıyla, Polonya, Romanya, Litvanya ve Hollanda'da faaliyet gösteren 7 farklı işletmede çalışan 215 çalışan ile yapılan araştırmada (Bakker vd., 2016), YİKA, SİKA ve ZİGA boyutlarının işe adanmışlık üzerinde etkisi bulunmuşken, EİGA boyutunun herhangi bir etkisi tespit edilememiştir. Bununla birlikte, benzer sonuçlara pek çok araştırmada ulaşılmıştır (Siddiki, 2015; Harju vd., 2016; Chen vd., 2014; Brenninkmeijer ve Hekkert-Koning, 2015).

Yerli yazında, işe adanmışlık ile ilgili çok sayıda araştırma yapılmışken, iş becerikliliği ile ilgili çok fazla çalışma yapılmadığı anlaşılmaktadır. Bu çalışmalardan yalnızca birinde, iş becerikliliği ile işe adanmışlık ilişkisi üzerinde durulmuştur. Bu araştırmada, 136 beyaz yakalı personel örneklem olarak alınmış, iş becerikliliğinin SİKA boyutu dışındaki boyutları ile işe adanmışlık arasında düşük ve orta düzeyde ilişkiler bulunmuştur (Uysal vd. 2018).

Araştırma bulgularından yola çıkarak uygulayıcılar, çalışanların iş becerikliliği davranışlarının teşvik edilmesi için, geri bildirim, performans görüşmesi ve ödüllendirme gibi yönetsel araçlardan yararlanabilirler. Çalışanlardan yüksek performans beklentisinin karşılanabilmesi için çalışanların işe adanmalarının öncülü olan iş becerikliliğinin artırılmasına yönelik eğitimler düzenlenmelidir. Yöneticilerin bu süreçlerde koçluk ve danışmanlık yapmalarının yanı sıra, çalışanlar için iyi kurgulanmış iletişim 
kanallarının oluşturulması da gerekmektedir. Ayrıca çalışanlara, iş arkadaşlarının, yöneticilerinin ve örgütlerinin desteğinin olduğunun hissettirilmesi önem arz etmektedir.

Araştırmanın süre ve mali kısıtları olduğu kadar, kesitsel bir araştırma olması, verilerin eş zamanlı toplanması gibi önemli başka sınırlılıkları da mevcuttur. Bu araştırma, farklı özel sektörler işletmelerinde çalışan insan kaynakları yöneticileri ile yapılmış olup, kamu sektörü çalışanları ile de yapılabilir. Yerli yazında yeterli düzeyde çalışılmadığı anlaşılan iş becerikliliği değişkeni ile proaktif davranış, iyi oluş, işin anlamı, akış deneyimi, iş yükü, iş tatmini ve tükenmişlik gibi değişkenler kullanılarak, aracılık ve düzenleyicilik rollerinin test edilebileceği değerlendirilmektedir. 
EXTENDED ABSTRACT

\section{The Effect of Human Resource Manager's Job Crafting on Work Engagement}

Tahsin Akçakanat - Hasan Hüseyin Uzunbacak - Osman Kürşat Acar

Süleyman Demirel University

Job crafting, explained for the first time by Wrzesniewski and Dutton (2001, p.179), is defined as the employee's regulation of their limits of duty by changing the form or number of the activities they carry out while doing a job and shaping of their communicational limits by changing the social setting that they interact with while doing a job. Job crafting is explained as employees performing new and different tasks to improve the compatibility of their own needs, skills and preferences and escape the monotony of the job they are doing. It was also stated that these employees may make changes in their job forming relationships with people they think will be more useful for themselves or re-organizing their forms of work to do their jobs better (Wrzesniewski and Dutton, 2001: 180; Berg et al., 2008, p.). Job crafting is explained by the Theory of Work Design and the Job Demands-Resources Model. Tims et al. discussed job crafting in a four-factor construct (Mamak, 2018: 16-18). These four factors are Increasing Structural Job Resources (ISCR), Decreasing Hindering Job Demand (DHJD), Increasing Social Job Resource (ISJR) and Increasing Challenging Job Demands (ICJD).

In the most general sense, work engagement is employees' focus on their job by dedicating themselves physically, emotionally and cognitively (Kahn, 1990, p.694). In another definition, dedicated employees are described as those who do their job by internalizing it and getting buried in it, and as a result of this, have a positive and satisfying cognitive experience (Schaufeli and Bakker, 2006, p.702). Work engagement is an attitudinal and behavioral situation where employees are connected to and feel a desire and interest for the job they do by knowing what is expected of them and forming good relationships with those around them and approach it by passion, eagerness, effort and energy (Macey and Schneider, 
2008, p.4). Employees who are dedicated to their work were described as individuals who believe in themselves, have positive feedback about themselves, make their individual objectives compatible with the objectives of the organization, are satisfied with the job they do however tired and exhausted they feel, and are addicted to their job without being workaholics (Bakker and Demerouti, 2008, p.210). The concept of work engagement, as in the case of job crafting, is based on the Job Demands-Resources Model. Schaufeli (2002, p.74-75), discussed work engagement in a threefactor construct including vigor, dedicating and absorption. Vigor refers to the employee's continuation of showing effort for their job with patience and will in an energic and psychologically durable way even if they face difficulties while doing their job. Dedicating is the employee's way of working with feelings of pride, passion and defiance by paying meaning and value to their job. Internalization is the complete focus of the employee on their job and their deep dedication to the job.

The relationship between job crafting and work engagement is discusses, as mentioned before, in the context of the Job Demands-Resources Theory. Job crafting is a situation that emerges as a result of the display of proactive behaviors by employees. This situation improves job resources by affecting their emotions that are related to their job and affects their feelings of dedication to the job (Bakker et al., 2011; Petrou et al., 2012; Tims et al., 2012, Uysal et al., 2018). In other words, job crafting behaviors dynamically lead employees to be busier with their job. This dynamism and effort may cause employees to act with the feeling of dedication towards their job (Van Wingerden and Poell, 2017, p.3).

The sample of this study consisted of 230 human resources managers that worked at various sectors in the Mediterranean Region in Turkey. The sample was determined by considering that human resources managers have to show job crafting skills as a requirement of their job. The study used the Job Crafting Scale which consist of 21 items and 4 dimensions that was developed by Tims et al. (2012). Adaptation of the scale into Turkish was studied by Akın et al. (2014). The study also used the Work Engagement Scale developed by Schaufeli and Bakker (2003) that consists of 3 dimensions and 9 items. This scale was adapted into Turkish by Özkalp and Meydan (2015). 
In the study, firstly a confirmatory factor analysis (CFA) was applied on the Job Crafting and Work Engagement Scales. As a result of the CFA, it was determined that the goodness of fit values of the scales were within acceptable limits. When the reliability levels of the scales based on their dimensions were examined, their internal consistency coefficients were found to be higher than .70 .

A hierarchical regression analysis was carried out with the purpose of testing the hypotheses. Accordingly, when the demographic variables were controlled, ISCR $(\beta=.270, \mathrm{p}<.001)$, ISJR $(\beta=.173, \mathrm{p}<.001)$ and ICJD $(\beta=.132, p<.05)$ predicted vigor positively and significantly. The dimension DHJD ( $\beta=-.059, \mathrm{p}>.05)$ did not have a significant effect on vigor. In the analysis on the dimension of dedicating, ISCR $(\beta=.271, \mathrm{p}<.001)$, ISJR $(\beta=.155, \mathrm{p}<.05)$ and ICJD $(\beta=.186, \mathrm{p}<.01)$ were found to predict dedicating positively and significantly. The dimension DHJD $(\beta=-.063, \mathrm{p}>.05)$ did not have a significant effect on the dimension of dedicating. Finally, in the analysis of the dimension of absorption, ISCR $(\beta=.030, \mathrm{p}>.05)$, DHJD ( $\beta=$ $.061, \mathrm{p}>.05)$ and ISJR $(\beta=.072, \mathrm{p}>.05)$ were found to predict internalization significantly. However, the dimension ICJD $(\beta=.238$, $\mathrm{p}<.001)$ did not have a significant effect on absorption.

\section{Kaynakça / References}

Akın, A., Sarıçam, H., Kaya, Ç., ve Demir, T. (2014). Turkish version of the Job Crafting Scale (JCS): Validity and reliability study. International Journal of Educational Researchers (IJERS), 5(1), 10-15.

Anderson, J. C., ve Gerbing, D. W. (1984). The effect of sampling error on convergence, improper solutions, and goodness-of-fit indices for maximum likelihood confirmatory factor analysis. Psychometrika, 49(2), 155-173.

Anderson, J. C., ve Gerbing, D. W. (1988). Structural equation modeling in practice: a review and recommended two-step approach. Psychological Bulletin, 103(3), 411-423.

Bakker, A. B., ve Demerouti, E. (2007). The job demands-resources model: State of the art. Journal of Managerial Psychology, 22, 309-328. 
Bakker, A. B., ve Demerouti, E. (2008). Towards a model of work engagement. Career Development International, 13(3), 209-223.

Bakker, A. B., Demerouti, E., ve Verbeke, W. (2004). Using the Job Demands-Resources model to predict burnout and performance, $\mathrm{Hu}$ man Resource Management, 43, 83-104

Bakker, A. B., L. Albrecht, S. L., ve Leiter, M. (2011). Key questions regarding work engagement. European Journal of Work and Organizational Psychology, 20(1), 4-28.

Bakker, A. B., Rodríguez-Muñoz, A., ve Sanz Vergel, A. I. (2016). Modelling job crafting behaviours: Implications for work engagement. Human Relations, 69(1), 169-189.

Bakker, A. B., Tims, M., ve Derks, D. (2012). Proactive personality and job performance: The role of job crafting and work engagement. $\mathrm{Hu}$ man Relations, 65(10), 1359-1378.

Balay, R. (2014). Yönetici ve öğretmenlerde örgütsel bağl1lık. 2. Baskı. Ankara: Pegem Akademi

Berg, J. M., Dutton, J. E., ve Wrzesniewski, A. (2008). What is job crafting and why does it matter. Positive Organizational Scholarship Theory to Practice Briefing, 1-8.

Brenninkmeijer, V., ve Hekkert-Koning, M. (2015). To craft or not to craft: The relationships between regulatory focus, job crafting and work outcomes. Career Development International, 20(2), 147-162.

Chen, C. Y., Yen, C. H., ve Tsai, F. C. (2014). Job crafting and job engagement: The mediating role of person-job fit. International Journal of Hospitality Management, 37, 21-28.

Christian, M. S., Garza, A. S., ve Slaughter, J. E. (2011). Work engagement: a meta-analytic review and directions for research in an emerging area. Personnel Psychology, 64, 89-136.

DeGroot, T., Kiker, D. S., ve Cross, T. C. (2000). A meta-analysis to review organizational outcomes related to charismatic leadership. Canadian Journal of Administrative Sciences, 17(4), 356-372.

Demerouti, E., Bakker, A. B., ve Gevers, J. M. (2015). Job crafting and extra-role behavior: The role of work engagement and flourishing. Journal of Vocational Behavior, 91, 87-96. 
Demerouti, E., Bakker, A. B., Nachreiner, F., ve Schaufeli, W. B. (2001). The job demands-resources model of burnout. Journal of Applied Psychology, 86, 499-512.

Field, A. (2009). Discovering statistics using SPSS. London: Sage Publications.

Halbesleben, J. R. (2010). A meta-analysis of work engagement: Relationships with burnout, demands, resources, and consequences. Work engagement: A handbook of essential theory and research, 8(1), 102-117.

Harju, L. K., Hakanen, J. J., ve Schaufeli, W. B. (2016). Can job crafting reduce job boredom and increase work engagement? A three-year cross-lagged panel study. Journal of Vocational Behavior, 95, 11-20.

Jöreskog, K., ve Sörbom, D. (1993). LISREL 8: Structural equation modeling with the simplis command language. Chicago, IL: Scientific Software International Inc.

Kahn, W. A. (1990). Psychological conditions of personal engagement and disengagement at work. Academy of Management Journal, 33(4), 692724.

Kalaycı, Ş. (Ed). (2005). SPSS uygulamalı çok değişkenli istatistik teknikleri. Ankara: Asil Yayın Dağıtım.

Kim, H., Im, J., ve Qu, H. (2018). Exploring antecedents and consequences of job crafting. International Journal of Hospitality Management, 75, 18-26.

Kline, R. B. (1998). Principles and practice of structural equation modeling. New York: Guilford Press.

Lu, C. Q., Wang, H. J., Lu, J. J., Du, D. Y., ve Bakker, A. B. (2014). Does work engagement increase person-job fit? The role of job crafting and job insecurity. Journal of Vocational Behavior, 84(2), 142-152.

Luthans, F. (2002). The need for and meaning of positive organizational behavior. Journal of Organizational Behavior, 23(6), 695-706.

Macey, W. H., ve Schneider, B. (2008). The meaning of employee engagement. Industrial and Organizational Psychology, 1(1), 3-30.

Mamak, Y. B. (2018). Proaktif kişiliğin iş becerikliği, iş performansı ve duygusal bağlılık üzerindeki etkileri. Yayınlanmamış Yüksek Lisans Tezi, Hacettepe Üniversitesi Sosyal Bilimler Enstitüsü, Ankara. 
Morgan, G. A., Leech, N. L., Gloeckner, G. W., ve Barret, K. C. (2004). SPSS for introductory statistics: Use and interpretation, Second Edition, London: Lawrance Erlbaum Associates

Nunnally, J. C. (1978). Psychometric theory. New York: McGraw-Hill.

Özdamar, K. (1999). Paket programlar ile istatistiksel veri analizi. Eskişehir: Kaan Kitabevi.

Özkalp, E., ve Meydan, B. (2015). Schaufeli ve Bakker tarafından geliştirilmiş olan işe angaje olma ölçeğinin Türkçe'de güvenilirlik ve geçerliliğinin analizi. İş, Güç Endüstri İlişkileri ve İnsan Kaynakları Dergisi, 17(3), 1-19.

Petrou, P., Demerouti, E., Peeters, M. C. W., Schaufeli, W. B., ve Hetland, J. (2012). Crafting a job on a daily basis: Contextual correlates and the link to work engagement. Journal of Organizational Behavior, 33(8), 1120-1141.

Petrou, P., Demerouti, E., ve Schaufeli, W. B. (2015). Job crafting in changing organizations: Antecedents and implications for exhaustion and performance. Journal of Occupational Health Psychology, 20(4), 470-480.

Rastogi, M., ve Chaudhary, R. (2018). Job crafting and work-family enrichment: The role of positive intrinsic work engagement. Personnel Review, 47(3), 651-674.

Schaufeli, W. B. ve Bakker, A. B. (2004). Job demands, job resources, and their relationship with burnout and engagement: A multi-sample study. Journal of Organizational Behavior, 25(3), 293-315.

Schaufeli, W. B., Bakker, A. B., ve Salanova, M. (2006). The measurement of work engagement with a short questionnaire: A cross-national study. Educational and Psychological Measurement, 66(4), 701-716.

Schaufeli, W. B., Salanova, M., González-Romá, V., ve Bakker, A. B. (2002). The measurement of engagement and burnout: A two sample confirmatory factor analytic approach. Journal of Happiness Studies, 3(1), 71-92.

Seligman, M. E. P., ve Csikszentmihalyi, M. (2000). Positive psychology: An introduction. American Psychologist, 55(1), 5-14.

Siddiqi, M. A. (2015). Work engagement and job crafting of service employees influencing customer outcomes. Vikalpa, 40(3), 277-292. 
Tarım, M. (2018). Lider-üye ilişkilerinde kurulan bağın üyelerin bağlllık ve performansları üzerindeki etkileri: Nitel bir çalışma. İstanbul Ticaret Üniversitesi Sosyal Bilimler Dergisi, 17(33), 407-419.

Tims, M., ve Bakker, A. B. (2010). Job crafting: Towards a new model of individual job redesign. SA Journal of Industrial Psychology, 36(2), 19.

Tims, M., Bakker, A. B., ve Derks, D. (2012). Development and validation of the job crafting scale. Journal of Vocational Behavior, 80(1), 173186.

Tims, M., Bakker, A. B., ve Derks, D. (2013). The impact of job crafting on job demands, job resources, and well-being. Journal of Occupational Health Psychology, 18(2), 230.

Tims, M., Bakker, A. B., Derks, D., ve Van Rhenen, W. (2013). Job crafting at the team and individual level: Implications for work engagement and performance. Group ve Organization Management, 38(4), 427-454.

Uysal, B, Özçelik, G., ve Uyargil, C. (2018). Bireysel iş yapılandırmanın sonuçları: Bireysel iş yapılandırmanın psikolojik sermaye ve işe adanmışlık üzerindeki etkisinin değerlendirilmesi. Yönetim Bilimleri Dergisi, 16(32), 651-666.

Ürü Sanı, F. O., Çalışkan, S. C., Atan, Ö., ve Yozgat, U. (2013). Öğretim üyelerinin hizmetkâr liderlik davranışları ve ardılları üzerine bir araştırma. Ege Akademik Bakış, 13(1), 63-82.

Van Wingerden, J., ve Poell, R. F. (2017). Employees' perceived opportunities to craft and in-role performance: the mediating role of job crafting and work engagement. Frontiers in Psychology, 8, 1-9.

Van Wingerden, J., Derks, D., ve Bakker, A. B. (2015). The impact of personal resources and job crafting interventions on work engagement and performance. Human Resource Management, 56(1), 5167.

Wrzesniewski, A., ve Dutton, J. E. (2001). Crafting a job: Revisioning employees as active crafters of their work. Academy of Management Review, 26, 179-201. 
Yavuz, M. (2018). İş zanaatkârlı̆̆ı ile bireysel performans çıtıları arasındaki ilişkide çalışanların dışsal prestij ve kurum destek algılarının rolü. Yayınlanmamış Doktora Tezi, Marmara Üniversitesi Sosyal Bilimler Enstitüsü, İstanbul.

Zeijen, M. E., Peeters, M. C., ve Hakanen, J. J. (2018). Workaholism versus work engagement and job crafting: What is the role of self-management strategies?. Human Resource Management Journal, 28(2), 357-373.

Zhu, W., Chew, I. K., ve Spangler, W. D. (2005). CEO transformational leadership and organizational outcomes: The mediating role of human-capital-enhancing human resource management. The Leadership Quarterly, 16(1), 39-52.

\section{Kaynakça Bilgisi / Citation Information}

Akçakanat, T., Uzunbacak, H. H. ve Acar, O. K. (2019). İnsan kaynakları yöneticilerinin iş becerikliliklerinin işe adanmışlıkları üzerine etkisi. OPUS-Uluslararası Toplum Araştırmaları Dergisi , 10(17), 395419. DOI: 10.26466/opus.513340 